\title{
Chromosomal abnormalities and copy number variations in fetal ventricular septal defects
}

Meiying Cai, Hailong Huang, Linjuan Su, Na Lin, Xiaoging Wu, Xiaorui Xie, Gang An, Ying Li, Yuan Lin, Liangpu $\mathrm{Xu}^{*}$ and Hua Cao*

\begin{abstract}
Background: This study aimed to evaluate the applicability of chromosomal microarray analysis (CMA), rather than traditional chromosome analysis, in prenatal diagnosis of ventricular septal defects (VSDs) for superior prenatal genetic counseling and to reveal a potential correlation between submicroscopic chromosomal aberrations and VSDs.

Results: Among the 151 VSD cases, 79 (52.3\%) had isolated defects and 72 (47.7\%) had additional ultrasound anomalies. Karyotype analysis identified 16 chromosomal abnormalities. Besides the 14 cases of chromosome abnormalities consistent with karyotype analysis, CMA identified an additional 20 cases (13.2\%) of abnormal copy number variations (CNVs), of which 13 were pathogenetic CNVs, 5 were variations of uncertain clinical significance (VOUS) and 2 were benign CNVs. The detection rate of pathogenic CNVs in non-isolated-VSDs was significantly higher than that in isolated-VSDs (36.1\% (26/72) vs. 1.3\% (1/79), $p=0.001)$. We also found that CMA results indicating pathogenic abnormalities affected the rate of pregnancy termination.
\end{abstract}

Conclusions: This study showed that CMA combined with cytogenetic analysis is particularly effective in identifying CNVs in fetuses with VSDs and can have an effect on obstetrical outcomes. The elucidation of the etiology of VSDs suggested that gene mutations or other factors may be implicated.

Keywords: Ventricular septal defects, Chromosomal microarray analysis, Chromosomal abnormality, Prenatal diagnosis

\section{Background}

Congenital heart disease (CHDs) is one of the most common types of birth defects, affecting up to 8 in every 1000 babies born in the China [1]. Ventricular septal defects (VSDs) are the most common cardiac defects seen postnatally, accounting for $30-35 \%$ of all CHDs detected after birth and $10 \%$ of all fetal cases [2,3]. Recent studies have shown that approximately $20-40 \%$ of VSDs are attributable to chromosomal aneuploidies or Mendelian diseases, while the remaining are attributable to non-Mendelian causes that are poorly understood [4-7]. Prenatal ultrasonography suggested that $33-47 \%$ percent of fetuses with

\footnotetext{
* Correspondence: xiliangpu@fjmu.edu.cn; caohua69@hotmail.com Department of the Prenatal Diagnosis Center, Fujian Provincial Maternity and Children's Hospital, affiliated hospital of Fujian Medical University, Fujian Key Laboratory for Prenatal Diagnosis and Birth Defect, Fuzhou, China
}

VSD had chromosomal abnormalities, among which trisomy 18 , trisomy 21 , and DiGeorge syndrome were the most common $[5,8]$.

Genomic microarrays include micro-array based comparative genomic hybridization $(\mathrm{aCGH})$ and single nucleotide polymorphism (SNP) arrays, both of which can detect micro-deletions and micro-duplications in the genome. Aside from the detection of CNVs, SNP arrays can detect uniparental disomy and chimeric DNA. In this study, we performed whole-genome scanning using SNP arrays as well as karyotyping of 151 fetuses that were diagnosed as having VSD by ultrasonic cardiography. We tried to elucidate genetic factors that cause fetal VSD and explore the clinical value of the application of CMA in the diagnosis of VSD in fetuses.

(c) The Author(s). 2018 Open Access This article is distributed under the terms of the Creative Commons Attribution 4.0 International License (http://creativecommons.org/licenses/by/4.0/), which permits unrestricted use, distribution, and reproduction in any medium, provided you give appropriate credit to the original author(s) and the source, provide a link to the Creative Commons license, and indicate if changes were made. The Creative Commons Public Domain Dedication waiver (http://creativecommons.org/publicdomain/zero/1.0/) applies to the data made available in this article, unless otherwise stated. 


\section{Methods}

\section{Patient data}

We conducted a retrospective study on VSD cases diagnosed prenatally with ultrasound in the Prenatal Diagnosis Center of the Fujian Provincial Maternal and Children Health Hospital, from January 2017 to April 2018. Fetal samples were collected by amniocentesis $(n=85)$ or cord blood sampling $(n=66)$ depending on the gestation period. Amniotic fluid was collected by amniocentesis at the gestational age of 16-24 weeks and fetal blood was collected by cord blood sampling at a gestational age over 24 weeks. The fetuses underwent a routine ultrasonic scan, and fetal biometry was performed at a median gestational age of $25+5$ (range, $18+3$ to $33+4$ ) weeks. This study was approved by the ethics committee at the Fujian Provincial Maternal and Child Health Hospital, and informed consent was obtained from the parents for invasive prenatal diagnosis. Once fetal pathogenic CNVs were confirmed, approximately $2.0 \mathrm{~mL}$ of peripheral venous blood was collected from their parents. DNA was extracted using the Gentra Puregene blood kit (QIAGEN, Santa Clara, CA, USA).

The cases were classified as isolated or non-isolatedVSD, the latter comprising cases with other cardiac anomalies, extracardiac structural anomalies, or sonographic soft markers. A total of 151 VSD cases were included, of which 79 (52.3\%) cases were isolated-VSD and 72 (47.7\%) cases were non-isolated-VSD (detailed information in Table 1).

\section{Cytogenetic analysis}

Cultured amniocytes or lymphocytes were analyzed by regular karyotype analysis using the Giemsa banding technique at a resolution of 450-550 bands.

\section{CMA}

Genomic DNA was directly extracted from uncultured amniotic fluid and cord blood samples using the QIAamp DNA Blood Mini kits (Qiagen, Germany). DNA was quantified using a NanoDrop spectrophotometer (Thermo Fisher Scientific, Waltham, MA, USA), according to the manufacturer's instructions. The DNA quality was assessed by agarose gel electrophoresis. The genome-wide high-resolution SNP array CytoScan HD (Affymetrix Genome CytoScan $750 \mathrm{~K}$,
Affymetrix, Santa Clara, CA, USA) including both SNPs and oligonucleotide probes was used in this study. DNA (250 ng) was amplified, labeled, and hybridized according to the manufacturer's protocol. Procedures for DNA digestion, ligation, polymerase chain reaction (PCR), fragmentation, labeling, and hybridization to the arrays were performed according to the manufacturer's protocols. The CNV reporting filter was set at $>100 \mathrm{~kb}$ in size with a minimum set of 50 marker counts. The results obtained from the CytoScan arrays were analyzed with Chromosome Analysis Suite software (Affymetrix), using annotations of the genome version GRCH37 (hg19). The detected copy number gains or losses were systematically evaluated by comparing them with values available in the literature and the publicly available databases, including database of genomic variants (DGV, http://projects.tcag.ca/variation/), DECIPHER database (http:// decipher.sanger.ac.uk/), the International Standards for Cytogenomic Arrays (ISCA, https://www.iscaconsortium.org/), and Online Mendelian Inheritance in Man (OMIM, http://www.omim.org). The CNVs were classified as benign, pathogenic, or variants of uncertain significance (VOUS) according to the American College of Medical Genetics (ACMG) guidelines [9]. Microarray analysis of DNA from maternal and paternal blood samples was used to determine whether CNVs detected in the fetal samples were inherited or de novo. All de novo CNVs were experimentally validated by fluorescence in situ hybridization (FISH).

\section{Statistical analysis}

IBM SPSS Statistics 20 (IBM, Armonk, NY, USA) was used for statistical analysis. The detection rate of pathogenic variants in the isolated and non-isolated-VSD fetuses was compared between cytogenetic analysis and CMA. A value of $p<0.05$ was considered statistically significant.

\section{Results \\ Cytogenetic analysis of VSD fetuses}

In the $151 \mathrm{VSD}$ cases analyzed, karyotyping identified 16 chromosomal abnormalities. Among the 79 isolated-VSD fetuses, karyotyping identified only one chromosomal abnormality associated with $13 \mathrm{p}+$, which was not found with CMA. However, of the 72 non-isolated-VSD fetuses,

Table 1 Phenotypic characteristics of 151 VSD fetuses

\begin{tabular}{|c|c|c|c|c|c|}
\hline \multirow[t]{2}{*}{ Classification } & \multirow{2}{*}{$\begin{array}{l}\text { Number of } \\
\text { fetuses }\end{array}$} & \multirow{2}{*}{$\begin{array}{l}\text { Number of Karyotype } \\
\text { abnormality }\end{array}$} & \multicolumn{3}{|l|}{ Number of CHA } \\
\hline & & & Pathogenic CNVs & VOUS & Benign CNVs \\
\hline Isolated-VSD & 79 & 1 & 1 & 1 & 1 \\
\hline Non-isolated-VSD & 72 & 15 & 12 & 4 & 1 \\
\hline Total & 151 & 16 & 13 & 5 & 2 \\
\hline
\end{tabular}

CMA chromosomal microarray analysis, CNVs copy number variations, VOUS variation of uncertain clinical significance, VSD ventricular septal defect 
karyotyping identified 15 clinically significant chromosomal abnormalities, involving trisomy $18(n=5)$, trisomy $21(n=2)$, trisomy $13(n=1)$, Klinefelter syndrome $(n=1)$, deletions of 4q25q28 ( $n=1)$, and duplications of $16 \mathrm{p} 13.3$ $(n=1), 22 \mathrm{q} 11.2(n=1)$, and $8 \mathrm{q} 21(n=1)$, and an unual partial aneuploidy- monosomy 18 and trisomy 18 with one chromosome exhibiting a 18p11.32p11.31 microdeletion and 18p11.31p11.21 duplication. Additionally, we found one pericentric (9)(p12q13) inversion, which was not found with CMA (Table 2).

\section{Detection rates of CMA with karyotyping}

CMA was performed in 151 VSD fetuses, with $22.5 \%$ (34/ 151) of the cases showing chromosomal abnormalities. Fourteen of these cases were also identified with the karyotype analysis, but the other 20 were identified only with CMA, of which 13 were pathogenetic CNVs, 5 were VOUS, and 2 were benign CNVs. Among the 13 fetuses with pathogenic CNVs, only one fetus had isolated-VSD. These $13 \mathrm{CNVs}$ involved deletions of 3q24q25.1, 15q24.1q24.2, and 22q11.21; duplications of 3q29, 7q11.23, 17p11.2, 22q11.21, 22q11.1q11.21, and $\mathrm{Xp28}$; and loss of heterozygosity of 16q23.2q24.3 and 16p13.3p12.3. There were 7 cases with pathogenic CNVs related to known chromosomal disorder syndromesDiGeorge syndrome $(n=4)$, Schmid-Fraccaro syndrome $(n=2)$, and Potocki-Lupski syndrome $(n=1)$ (Table 3$)$.

\section{Comparison of pathogenic CNV detection rates}

Overall, the detection rate of pathogenic CNVs with CMA was significantly higher than that with karyotype analysis (17.9\% vs. $10.6 \%, p<0.05)$. The detection rate of CNVs in non-isolated-VSDs was significantly higher than that in isolated-VSDs $(36.1 \%(26 / 72)$ vs. $1.3 \%(1 / 79), p=0.001)$.

\section{Inheritance analysis and obstetrical outcomes}

We screened the hereditary information of 27 families in which karyotyping showed chromosomal abnormalities (9 cases of chromosome aneuploidies were exempted) and abnormal CNVs. Parental analysis showed that that in 5 fetuses the abnormalities were inherited from unaffected parents (Table 4), and in 18 cases, the CNVs occurred de novo. The reasons for termination of pregnancies in the 28 women analyzed were chromosome abnormalities $(n=$ $14)$, pathogenic CNVs $(n=13)$, and VOUS CNVs $(n=1)$. We also found that in $2.5 \%(2 / 79)$ of isolated-VSD cases and $44.4 \%(32 / 72)$ of non-isolated-VSD cases, pregnancy was terminated.

\section{Discussion}

The development of CMA technology, including aCGH and SNP arrays, in the early 2000s provided a new research tool for chromosomal analysis. Since then, a number of studies have used CMA to locate novel candidate genes involved in heterotaxy [10], isolated tetralogy of

Table 2 Abnormal karyotyping results of VSD fetuses

\begin{tabular}{|c|c|c|c|c|}
\hline Case & Karyotype & CMA results & Prenatal ultrasound & Postnatal outcome \\
\hline 1 & $47, X X,+18$ & $\operatorname{arr}[$ hg19] $(18) \times 3$ & $\begin{array}{l}\text { VSD; Posterior fossa widening; Single } \\
\text { umbilical artery }\end{array}$ & TP \\
\hline 2 & $47, X X,+18$ & $\operatorname{arr}[$ hg19] $(18) \times 3$ & VSD; TS; FGR & $\mathrm{TP}$ \\
\hline 3 & $47, X X,+18$ & $\operatorname{arr}[$ hg19] $(18) \times 3$ & VSD; ARA; TS; Absence of nasal bone & $\mathrm{TP}$ \\
\hline 4 & $47, X Y,+18$ & $\operatorname{arr}[$ hg19] $(18) \times 3$ & VSD; Single umbilical artery; FGR & $\mathrm{TP}$ \\
\hline 5 & $47, X Y,+18$ & $\operatorname{arr}[$ hg19] $(18) \times 3$ & $\begin{array}{l}\text { VSD; FGR; Absence of nasal bone; } \\
\text { Overriding fingers }\end{array}$ & $\mathrm{TP}$ \\
\hline 6 & $47, X Y,+21$ & $\operatorname{arr}[$ hg19] $(21) \times 3$ & VSD; ARA; PVS; Absence of nasal bone & $\mathrm{TP}$ \\
\hline 7 & $47, X Y,+21$ & $\operatorname{arr}[$ hg19] $(21) \times 3$ & VSD; TGA & $\mathrm{TP}$ \\
\hline 8 & $47, X Y,+13$ & $\operatorname{arr}[$ hg19](13) $\times 3$ & VSD; COA; LSVC; Single umbilical artery & $\mathrm{TP}$ \\
\hline 9 & $47, X X Y$ & $\operatorname{arr}[$ hg 19] $(1-22) \times 2,(X X Y) \times 1$ & VSD; FGR & $\mathrm{TP}$ \\
\hline 10 & $46, X X,-18,+$ mar & $\begin{array}{l}\text { arr[hg19]18p11.32p11.31(136,227-3,348,254) × } \\
1,18 p 11.31 p 11.21(3,350,736-13,083,388) \times 3\end{array}$ & VSD; COA; PVS; AOO & $\mathrm{TP}$ \\
\hline 11 & $46, X Y$, del,(4)(q25q28) & $\operatorname{arr}[$ hg 19]4q25q28.1(112,192,577-127,874,789) × 1 & VSD; widening of left lateral ventricle & $\mathrm{TP}$ \\
\hline 12 & $46, X Y, \operatorname{add}(16)(\mathrm{p} 13.3)$ & $\begin{array}{l}\operatorname{arr}[\text { hg19]16P13.3(85,880-536,631) × 1,17q24.2q25.3 } \\
(64,966,574-81,041,823) \times 3\end{array}$ & $\begin{array}{l}\text { VSD; LSVC; widening of left lateral } \\
\text { ventricle }\end{array}$ & $\mathrm{TP}$ \\
\hline 13 & $47, X Y, \operatorname{add}(22)(q 11.1)$ & $\operatorname{arr}[$ hg19]22q11.1q11.21(16,888,899-18,649,190) × 4 & VSD; HA; Single umbilical artery & $\mathrm{TP}$ \\
\hline 14 & $46, X X, \operatorname{add}(8)(q 21)$ & $\operatorname{arr}[$ hg19]8q21.2q23.3(86,553,128-114,877,447) × 3 & VSD; PTA & $\mathrm{TP}$ \\
\hline 15 & $46, X X$, inv.(9)(p12q13) & $\operatorname{arr}[$ hg19] $(1-22) \times 2,(X X) \times 1$ & VSD; choroid plexus cysts & TD \\
\hline 16 & $46, X Y, 13 p+$ & $\operatorname{arr}[$ hg19] $(1-22) \times 2,(X Y) \times 1$ & VSD & TD \\
\hline
\end{tabular}

$A O O$ augmentation of oval, $A R A$ aortic ride across, COA coarctation of the aorta, CMA chromosomal microarray analysis, FGR fetal growth restriction, $H A$ hypoplastic aorta, HLHS hypoplastic left heart syndrome, LSVC left superior vena cava, PTA persistent truncus arteriosis, PVS pulmonary valve stenosis, SV single ventricle, TD term delivery, TGA transposition of the great arteries, TP termination of pregnancy, TS tricuspid stenosis, VSD ventricular septal defect 
Table 3 Chromosomal microarray analysis of VSD fetuses with normal karyotyping results

\begin{tabular}{|c|c|c|c|c|c|c|}
\hline Case & CMA results & $\begin{array}{l}\text { Size } \\
(\mathrm{Mb})\end{array}$ & Prenatal ultrasound & $\begin{array}{l}\text { Pathogenicity } \\
\text { classification }\end{array}$ & $\begin{array}{l}\text { Obstetrical } \\
\text { outcomes }\end{array}$ & Inheritance \\
\hline 1 & arr[hg19]22q11.21(18,648,855-21,800,471) × 1 & 3.1 & $\begin{array}{l}\text { VSD; RAA; vascular circle; } \\
\text { ALSA }\end{array}$ & $\begin{array}{l}\text { P (DiGeorge } \\
\text { syndrome) }\end{array}$ & TP & de novo \\
\hline 2 & $\operatorname{arr}[$ hg19]22q11.21 $(18,648,855-21,800,471) \times 1$ & 3.1 & $\begin{array}{l}\text { VSD; ARA; PA; thymic } \\
\text { hypoplasia }\end{array}$ & $\begin{array}{l}\text { P (DiGeorge } \\
\text { syndrome) }\end{array}$ & $\mathrm{TP}$ & de novo \\
\hline 3 & arr[hg19]22q11.21(18,631,364-20,729,389) × 1 & 2.0 & VSD; thymic hypoplasia & $\begin{array}{l}\text { P (DiGeorge } \\
\text { syndrome) }\end{array}$ & $\mathrm{TP}$ & de novo \\
\hline 4 & $\operatorname{arr}[$ hg19]22q11.21(18,648,855-21,800,471) × 1 & 3.1 & VSD; RAA & $\begin{array}{l}\text { P (DiGeorge } \\
\text { syndrome) }\end{array}$ & $\mathrm{TP}$ & de novo \\
\hline 5 & $\operatorname{arr}[$ hg19]22q11.21 $(18,648,855-21,800,471) \times 1$ & 3.1 & $\begin{array}{l}\text { VSD; ARSA; TR; LSVC; } \\
\text { Single umbilical artery }\end{array}$ & P (Cat Eye Syndrome) & $\mathrm{TP}$ & de novo \\
\hline 6 & $\operatorname{arr}[$ hg19]22q11.1q11.21 $(16,888,899-18,649,190) \times 4$ & 1.7 & $\begin{array}{l}\text { VSD; ARSA; TR; LSVC; } \\
\text { Single umbilical artery }\end{array}$ & P (Cat Eye Syndrome) & TP & de novo \\
\hline 7 & $\operatorname{arr}[$ hg 19]17p11.2(16,567,623-18,743,354) ×3 & 2.1 & VSD; PA; FGR & $\begin{array}{l}\text { P (Potocki-Lupski } \\
\text { Syndrome) }\end{array}$ & $\mathrm{TP}$ & de novo \\
\hline 8 & arr[hg19]Xp28(152,713,658-153,421,838)×3 & 0.69 & VSD; TR & $P$ & $\mathrm{TP}$ & de novo \\
\hline 9 & $\operatorname{arr}[$ hg 19]3q24q25.1 $(143,476,996-151,222,561) \times 1$ & 7.7 & $\begin{array}{l}\text { VSD; ocular hypertelorism; } \\
\text { widening of lateral ventricle }\end{array}$ & $P$ & TP & de novo \\
\hline 10 & $\operatorname{arr}[$ hg19]15q24.1q24.2(72,965,465-75,567,135) × 1 & 2.6 & $\begin{array}{l}\text { VSD; PA; FGR; Absence of } \\
\text { nasal bone }\end{array}$ & $P$ & TP & de novo \\
\hline 11 & $\operatorname{arr}[$ hg19]3q29(195,743,957-197,386,180) × 3 & 1.6 & VSD & $P$ & $\mathrm{TP}$ & de novo \\
\hline 12 & $\operatorname{arr}[$ hg19]7q11.23(72,701,098-74,069,645) ×3 & 1.3 & VSD; Left kidney dysplasia & $P$ & TP & de novo \\
\hline 13 & $\begin{array}{l}\text { arr[hg19]16q23.2q24.3(79,800,878- } \\
90,146,366) \mathrm{hmz}, 16 \mathrm{p} 13.3 \mathrm{p} 12.3(94,807-19,302,326) \mathrm{hmz}\end{array}$ & 10.3 & $\begin{array}{l}\text { VSD; PVS; Left kidney dysplasia; } \\
\text { FGR }\end{array}$ & $P$ & TP & UPD \\
\hline 14 & arr[hg19]11P15.1P14.3(20,745,930-21,780,075) ×3 & 1.0 & $\begin{array}{l}\text { VSD; Right hydronephrosis; } \\
\text { widening of left lateral ventricle }\end{array}$ & VOUS & $\mathrm{TP}$ & De novo \\
\hline 15 & $\operatorname{arr}[$ hg19]4q24(106,284,925-107,545,257) ×3 & 1.2 & VSD; ARSA; FGR & VOUS & $\mathrm{TD}$ & De novo \\
\hline 16 & arr[hg19]9q21.33q22.1 $(89,868,507-90,975,015) \times 3$ & 1.1 & VSD & VOUS & TD & De novo \\
\hline 17 & $\operatorname{arr}[$ hg19]16p13.11(14,897,401-16,534,031) × 1 & 0.5 & $\begin{array}{l}\text { VSD; Left ventricular } \\
\text { hyperechoic }\end{array}$ & VOUS & TD & De novo \\
\hline 18 & $\operatorname{arr}[$ hg19]2q31.2q31.3(180,558,684-181,901,189) ×3 & 0.5 & VSD; OFB & VOUS & $\mathrm{TD}$ & De novo \\
\hline 19 & $\operatorname{arr}[$ hg19]5q14.1 $(76,983,283-77,512,158) \times 3$ & 0.5 & VSD & B & $\mathrm{TD}$ & Maternal \\
\hline 20 & $\operatorname{arr}[$ hg 19]10q21.1 $(59,095,330-60,684,488) \times 1$ & 1.5 & VSD; TR & B & TD & Maternal \\
\hline
\end{tabular}

ALSA aberrant left subclavian artery, ARA aortic ride across, ARSA aberrant right subclavian artery, $B$ benign, CMA chromosomal microarray analysis, CNVs copy number variations, FGR fetal growth restriction, $L S V C$ left superior vena cava, OFB oval flaps bulging, $P$ Pathogenic, $P A$ pulmonary atresia, $P V S$ pulmonary valve stenosis, RAA right aortic arch, TR tricuspid regurgitation, TD term delivery, TP termination of pregnancy, UPD uniparental disomy, VOUS variation of uncertain clinical significance, VSD ventricular septal defect, VC vascular circle

Table 4 Chromosomal abnormalities inherited from unaffected parents in VSD fetuses

\begin{tabular}{|c|c|c|c|c|c|}
\hline Case & Prenatal ultrasound & Abnormal fetal chromosomes & $\begin{array}{l}\text { Pathogenicity } \\
\text { classification }\end{array}$ & Inheritance & $\begin{array}{l}\text { Postnatal } \\
\text { outcome }\end{array}$ \\
\hline 1 & VSD & $46, X X$,inv.(9)(p12q13) & B & Maternal & TD \\
\hline 2 & VSD & $46, X Y, 13 p s t k+$ & B & Maternal & TD \\
\hline 3 & VSD, TR & $\operatorname{arr}[$ hg19]5q14.1 $(76,983,283-77,512,158) \times 3$ & B & Maternal & TD \\
\hline 4 & VSD, single umbilical artery & $\operatorname{arr}[$ hg19]10q21.1 $(59,095,330-60,684,488) \times 1$ & $\mathrm{B}$ & Maternal & TD \\
\hline 5 & VSD, RAA, left kidney dysplasia & $\begin{array}{l}\operatorname{arr}[\mathrm{hg} 19] 16 \mathrm{q} 23.2 \mathrm{q} 24.3(79,800,878- \\
90,146,366) \mathrm{hmz}, 16 \mathrm{p} 13.3 \mathrm{p} 12.3(94,807-19,302,326) \mathrm{hmz}\end{array}$ & $\mathrm{P}(\mathrm{LOH})$ & Maternal Normal phenotype & TP \\
\hline
\end{tabular}

$B$ benign, $P$ pathogenic, $R A A$ right aortic arch, $T D$ term delivery, $T P$ termination of pregnancy, $T R$ tricuspid regurgitation, VSD ventricular septal defect, $L O H$ loss of heterozygosity 
Fallot (TOF) [11], and left-sided CHD [12], as well as novel genomic regions of interest [13]. However, little is known about the involvement of CNVs in either isolated or non-isolated-VSDs. Therefore, we used CMA combined with cytogenetic analysis to identify chromosomal abnormalities and CNVs in fetuses with VSDs, for superior prenatal genetic counseling and revealed a potential correlation between submicroscopic chromosomal aberrations and VSDs.

VSDs are attributable to both Mendelian diseases or chromosomal aneuploidies, as well as to non-Mendelian causes [2]. In our study, karyotype analysis identified 16 chromosomal abnormalities in 151 VSD cases. Among the isolated-VSD fetuses, karyotyping only identified one chromosomal abnormality associated with $13 \mathrm{p}+$, a type of heterochromatin polymorphism, which was not found with CMA. Heterochromatin is regarded as a morphological manifestation of genetic silencing [14]. However, in the non-isolated-VSD fetuses, karyotyping identified clinically significant chromosomal abnormalities involving trisomy 18 , trisomy 21 , trisomy 13 , Klinefelter syndrome, 22q11.2 deletion, and trisomy 18 with one chromosome exhibiting a 18p11.32p11.31 microdeletion and 18p11.31p11.21 duplication. A previous study has reported the association between VSD and major aneuploidies (trisomy 21, trisomy 18, trisomy 13, and Klinefelter syndrome), as well as 22q11.2 deletion syndrome [15], confirming our findings. Karyotype analysis also identified deletion of $4 \mathrm{q} 25 \mathrm{q} 28$, and duplications of 16 p13.3 and 8q21. These three chromosomal abnormalities are associated with abnormal cardiac development, according to the DECIPHER database. Additionally, we found one pericentric (9)(p12q13) inversion, which was not found with CMA. Some reports have predicted that the genes responsible for normal heart development could be present on chromosome 9, around the p11-q13 region, which might be rendered defective during the process of inversion and thereby resulted in CHD; however, this theory needs further study.

According to the study [16], CMA is unable to replace karyotype analysis due to its failure in detecting chromosome translocations or inversions. But CMA is superior to karyotype analysis because of its high accuracy and resolution in detecting and identifying $\mathrm{CNVs}$, without the need for amniotic fluid cell culture. We observed that the detection rate of pathogenic abnormalities with CMA was significantly higher than with karyotype analysis. According to some reported studies, the yield of CMA in prenatal evaluation ranges from 6.6 to $19.2 \%$ [17-20]. The actual rates of clinical detection in our cohort are consistent with the reported studies.

In this study, the most frequently detected CNVs in VSD cases were 22q11.2 deletions. CHDs are known to be associated with 22q11.2 microdeletion [21]. According to the DECIPHER database, TBX1 is the key causative gene for CHD phenotypes resulting from the 22q11.2 deletion. Besides 22q11.2 deletions, we identified two CNVs associated with Cat Eye Syndrome [22] and Potocki-Lupski Syndrome [23]. Patients with these syndromes display a range of physical and mental disabilities as well as CHDs, including VSDs. Although there is no reported correlation between $\mathrm{Xq} 28$ duplication and VSDs, this fragment is important for intellectual development and has been confirmed as a pathogenic $\mathrm{CNV}$ [24]. It is well accepted that when VSD is detected in the presence of other structural anomalies, it is more likely related to genetic disorders [25]. We identified a diverse set of four CNVs associated with rare chromosomal syndromes- 3q24q25.1 and 15q24.1q24.2 and the two microduplications, 3q29 and 7q11.23. These syndromes display a range of physical and mental disabilities as well as congenital organ malformations, including VSD. Syndromic VSDs are related to a variety of etiologies such as microscopic and sub-microscopic chromosomal abnormalities, monogenic syndromes, as well as epigenetic and environmental factors [26]. We also found one VSD case with loss of heterozygosity in 16q23.2q24.3 and 16p13.3p12.3. CMA on the parents showed that it was a result of maternal uniparental disomy, which was a classified pathogenic variation.

We observed five cases of VOUS. The result is consistent with the frequency reported in other studies using similar CMA [6, 18]. One case had a $1.0 \mathrm{Mb}$ duplication in chromosome 11p15.1p14.3 that involved an OMIM gene, NELL1, which is associated with the differentiation of brain cells and the growth, differentiation, and mineralization of osteoblasts. The parents' CMA results were normal. Thus, the fetal CNV was de novo, but its clinical significance is uncertain. Due to the non-isolated-VSDs with other severe ultrasound anomalies, the parents opted to terminate the pregnancy.We checked the reference genes involved in the other four cases of VOUS, and none of them are known to be associated with embryonic heart development.The parents opted to delivery the pregnancy. As the use of CMA for genetic disorders expands, increasing data on $\mathrm{CNVs}$ is expected to decrease the number of VOUS remarkably in the future.

In this study, the detection rate of CNVs in non-isolatedVSDs was significantly higher than that in isolated-VSDs. In contrast, An et al. [27] showed that there was no significant difference in the detection rate between isolated-VSD and not-isolated-VSD. One reason for the varying detection rates might be due to different prenatal ultrasound equipment and array probe scales. We found that $2.5 \%(2 / 79)$ of isolated-VSD cases and $44.4 \%$ (32/72) resulted with termination of pregnancy, with the reasons being chromosome abnormalities, pathogenic CNVs, and other severe ultrasound anomalies. We also found that pregnant women 
were more likely to continue pregnancy when known chromosomal abnormalities were excluded. This highlights the importance of improving genetic counseling, providing psychological support, and raising awareness of VSDs in parents to reduce unnecessary termination of pregnancies.

\section{Conclusion}

The accuracy of CMA testing is significant in cases of prenatally detected $\mathrm{CHD}$, for both isolated- and non-isolatedVSD cases. In conclusion, CMA combined with cytogenetic analysis is particularly effective in identifying chromosomal abnormalities and CNVs in fetuses with VSDs, which could aid parental counselling. Based on this study and others [28], a majority of the cases still remain elusive, suggesting that different gene mutations or other factors may be implicated in the etiology of VSDs.

\section{Abbreviations}

CHD: Congenital heart disease; CMA: Chromosomal microarray analysis; CNV: Copy number variation; FISH: Fluorescence in situ hybridization; LOH: Loss of heterozygosity; PCR: Polymerase chain reaction; SNP: Single nucleotide polymorphism; VOUS: Variation of uncertain clinical significance; VSD: Ventricular septal defects

\section{Acknowledgments}

We thank the patients that participated in this study.

\section{Funding}

This work was supported by the Key Special Projects of Fujian Provincial Department of Science and Technology [no. 2013YZ0002-1], the Key Clinical Specialty Discipline Construction Program of Fujian [no. 20121589], and the Fujian Provincial Natural Science Foundation [no. 2017 J01238].

\section{Availability of data and materials}

The datasets used and/or analysed during the current study are available from the corresponding author on reasonable request.

\section{Authors' contributions}

Study concepts: LX, HC; Study design: MC; CMA analysis: HH, GA; Karyotyping: XW, YL; FISH analysis: HH; Data analysis and interpretation: NL; Statistical analysis: XX, LS; Manuscript preparation: MC, LX. All authors read and approved the final manuscript.

\section{Ethics approval and consent to participate}

The research was approved by the ethics committee at the Fujian Provincial Maternal and Child Health Hospital, and informed consent was obtained from the parents for invasive prenatal diagnosis.

\section{Consent for publication}

Informed written consent was obtained from parents for publication for images and other clinical information relating to this case to be reported for academic purpose.

\section{Competing interests}

The authors declare that they have no competing interest.

\section{Publisher's Note}

Springer Nature remains neutral with regard to jurisdictional claims in published maps and institutional affiliations.
Received: 17 October 2018 Accepted: 20 November 2018

Published online: 28 November 2018

\section{References}

1. Lin KY, D'Alessandro LC, Goldmuntz E. Genetic testing in congenital heart disease: ethical considerations. World J Pediatr Congenit Heart Surg. 2013; 4(1):53-7.

2. Li G, Yang N, Xie M, Xu Y, Han N, Chen Q, et al. Perinatal and follow-up outcome study of fetal anomalies with multidisciplinary consultation. Ther Clin Risk Manag. 2017;13:1303-7.

3. Mosimann B, Zidere V, Simpson JM, Allan LD. Outcome and requirement for surgical repair following prenatal diagnosis of ventricular septal defect. Ultrasound Obstet Gynecol. 2014;44(1):76-81.

4. Paladini D, Palmieri S, Lamberti A, Teodoro A, Martinelli P, Nappi C. Characterization and natural history of ventricular septal defects in the fetus. Ultrasound Obstet Gynecol. 2000;16(2):118-22.

5. Axt-Fliedner R, Schwarze A, Smrcek J, Germer U, Krapp M, Gembruch U Isolated ventricular septal defects detected by color Doppler imaging: evolution during fetal and first year of postnatal life. Ultrasound Obstet Gynecol. 2006:27(3):266-73.

6. Du L, Xie HN, Huang LH, Xie YJ, Wu LH. Prenatal diagnosis of submicroscopic chromosomal aberrations in fetuses with ventricular septal defects by chromosomal microarray-based analysis. Prenat Diagn. 2016; 36(13):1178-84

7. Goldmuntz E. DiGeorge Syndrome: New Insights. Clin Perinatol. 2005;32(4): 963-78.

8. Paladini D, Russo M, Teodoro A, Pacileo G, Capozzi G, Martinelli P, et al. Prenatal diagnosis of congenital heart disease in the Naples area during the years 1994-1999 -- the experience of a joint fetal-pediatric cardiology unit. Prenat Diagn. 2002;22(7):545-52.

9. Hanemaaijer NM, Sikkema-Raddatz B, van der Vries G, Dijkhuizen T, Hordijk $R$, van Essen AJ, et al. Practical guidelines for interpreting copy number gains detected by high-resolution array in routine diagnostics. Eur J Hum Genet. 2012;20(2):161-5.

10. Thienpont B, Mertens L, de Ravel T, Eyskens B, Boshoff D, Maas N, et al. Submicroscopic chromosomal imbalances detected by array-CGH are a frequent cause of congenital heart defects in selected patients. Eur Heart J. 2007;28(22):2778-84

11. Breckpot J, Tranchevent LC, Thienpont B, Bauters M, Troost E, Gewillig M, et al. BMPR1A is a candidate gene for congenital heart defects associated with the recurrent 10q22q23 deletion syndrome. Eur J Med Genet. 2012; 55(1):12-6.

12. Hitz MP, Lemieux-Perreault LP, Marshall C, Feroz-Zada Y, Davies R, Yang SW, et al. Rare copy number variants contribute to congenital left-sided heart disease. PLoS Genet. 2012;8(9):e1002903.

13. Geng J, Picker J, Zheng Z, Zhang X, Wang J, Hisama F, et al. Chromosome microarray testing for patients with congenital heart defects reveals novel disease causing loci and high diagnostic yield. BMC Genomics. 2014;15: 1127

14. Elgin SC, Reuter G. Position-effect variegation, heterochromatin formation, and gene silencing in drosophila. Cold Spring Harb Perspect Biol. 2013;5(8): a017780.

15. Costain G, Silversides CK, Bassett AS. The importance of copy number variation in congenital heart disease. Npj Genom Med. 2016;1:16031.

16. Wapner RJ, Martin CL, Levy B, Ballif BC, Eng CM, Zachary JM, et al. Chromosomal microarray versus karyotyping for prenatal diagnosis. N Engl J Med. 2012;367(23):2175-84

17. Mademont-Soler I, Morales C, Soler A, Martínez-Crespo JM, Shen Y, Margarit E, et al. Prenatal diagnosis of chromosomal abnormalities in fetuses with abnormal cardiac ultrasound findings: evaluation of chromosomal microarray-based analysis. Ultrasound Obstet Gynecol. 2013;41(4):375-82.

18. Liao C, Li R, Fu F, Xie G, Zhang Y, Pan M, et al. Prenatal diagnosis of congenital heart defect by genome-wide high-resolution SNP array. Prenat Diagn. 2014;34(9):858-63.

19. Yan $Y$, Wu Q, Zhang L, Wang X, Dan S, Deng D, et al. Detection of submicroscopic chromosomal aberrations by array-based comparative genomic hybridization in fetuses with congenital heart disease. Ultrasound Obstet Gynecol. 2014;43(4):363.

20. Zhu X, Li J, Ru T, Wang Y, Xu Y, Yang Y, et al. Identification of copy number variations associated with congenital heart disease by chromosomal 
microarray analysis and next-generation sequencing. Prenat Diagn. 2016; 36(4):321-7.

21. Ferencz C, Neill CA, Boughman JA, Rubin JD, Brenner Jl, Perry LW. Congenital cardiovascular malformations associated with chromosome abnormalities: an epidemiologic study. J Pediatr. 1989;114(1):79-86.

22. Johnson A, Minoshima S, Asakawa S, Shimizu N, Shizuya H, Roe BA, et al. A 1.5-Mb Contig within the cat eye syndrome critical region at human chromosome 22q11.2. Genomics. 1999;57(2):306-9.

23. Potocki L, Bi W, Treadwell-Deering D, Carvalho CM, Eifert A, Friedman EM, et al. Characterization of Potocki-Lupski syndrome (dup(17)(p11.2p11.2)) and delineation of a dosage-sensitive critical interval that can convey an autism phenotype. Am J Hum Genet. 2007;80(4):633-49.

24. Amir RE, Van den Veyver IB, Wan M, Tran CQ, Francke U, Zoghbi HY. Rett syndrome is caused by mutations in X-linked MECP2, encodingmethyl-CpGbinding protein 2. Nat Genet. 1999:23(2):185-8

25. Donnelly JC, Platt LD, Rebarber A, Zachary J, Grobman WA, Wapner RJ Association of copy number variants with specific ultrasonographically detected fetal anomalies. Obstet Gynecol. 2014;124(1):83-90.

26. Sukenik-Halevy R, Sukenik S, Koifman A, Alpert Y, Hershkovitz R, Levi A, et al. Clinical aspects of prenatally detected congenital heart malformations and the yield of chromosomal microarray analysis. Prenat Diagn. 2016;36(13): 1185-91.

27. An Y, Duan W, Huang G, Chen X, Li L, Nie C, et al. Genome-wide copy number variant analysis for congenital ventricular septal defects in Chinese Han population. BMC Med Genet. 2016;9:2.

28. Song MS, Hu A, Dyamenahalli U, Chitayat D, Winsor EJ, Ryan G, et al. Extracardiac lesions and chromosomal abnormalities associated with major fetal heart defects: comparison of intrauterine, postnatal and postmortem diagnoses. Ultrasound Obstet Gynecol. 2009;33(5):552-9.

Ready to submit your research? Choose BMC and benefit from:

- fast, convenient online submission

- thorough peer review by experienced researchers in your field

- rapid publication on acceptance

- support for research data, including large and complex data types

- gold Open Access which fosters wider collaboration and increased citations

- maximum visibility for your research: over $100 \mathrm{M}$ website views per year

At $\mathrm{BMC}$, research is always in progress.

Learn more biomedcentral.com/submissions 